\title{
Is interleukin-1 $\propto$ a luteotrophic or luteolytic agent in cattle?
}

\author{
Magdalena Majewska, Izabela Woclawek-Potocka, Mamadou M Bah, Joanna Hapunik, Katarzyna \\ K Piotrowska, Yukari Tasaki ${ }^{1}$, Tomas J Acosta ${ }^{1}$, Kiyoshi Okuda ${ }^{1}$ and Dariusz J Skarzynski \\ Department of Reproductive Immunology and Pathology, Institute of Animal Reproduction and Food Research, \\ Polish Academy of Sciences, 10-747 Olsztyn, Poland and ${ }^{1}$ Laboratory of Reproductive Endocrinology, \\ Graduate School of Natural Science and Technology, Okayama University, Okayama 700-8530, Japan \\ Correspondence should be addressed to D J Skarzynski; Email: d.skarzynski@pan.olsztyn.pl
}

\begin{abstract}
Cytokines are thought to regulate prostaglandin (PG) secretion in the bovine endometrium. However, there is no consensus about the role of interleukin-1 $\alpha$ (IL1A) on PG secretion. The objective of this study was to examine the influence of IL1A on basal and interferon- $\tau$ (IFNT)-regulated PG in vitro secretion, as well its effects on PG secretion, progesterone $\left(\mathrm{P}_{4}\right)$ output, and corpus luteum (CL) in vivo lifespan. Explants of bovine endometrium (days 16-17 of the estrous cycle or early pregnancy) were stimulated with IL1A (10 ng/ml), IFNT (30 ng/ml), or IL1A combined with IFN. IL1A alone strongly stimulated luteotrophic PGE $_{2}$ secretion by endometrial tissues of both pregnant and nonpregnant cows. IL1A also stimulated luteolytic $\mathrm{PGF}_{2 \alpha}$ output in the late luteal phase. IFNT augmented the stimulatory

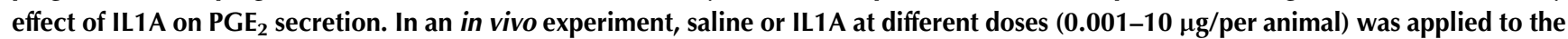

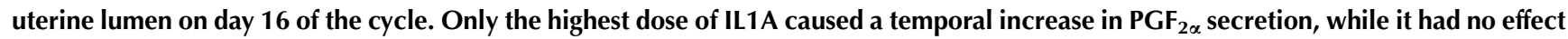
on $\mathrm{P}_{4}$ secretion or $\mathrm{CL}$ lifespan. Application of 0.1 and $1 \mu \mathrm{g}$ IL1A stimulated $\mathrm{P}_{4}$ and $\mathrm{PGE}_{2}$ output and prolonged the $\mathrm{CL}$ lifespan. Although IL1A may stimulate in vitro luteolytic $\mathrm{PGF}_{2 \alpha}$ secretion during the estrous cycle, it only acts as a luteotrophic factor in vivo. IL1A increased luteotrophic $\mathrm{PGE}_{2}$ and $\mathrm{P}_{4}$ output, inhibiting spontaneous luteolysis. These luteotrophic effects may result in appropriate luteal development and function in cows during the estrous cycle and early pregnancy.

Reproduction (2010) 139 665-672
\end{abstract}

\section{Introduction}

The cyclic nature of the bovine estrous cycle depends on endometrial prostaglandin (PG) production and its action on the corpus luteum (CL; McCracken et al. 1999, Skarzynski et al. 2008). PGs are synthesized from arachidonic acid in several organs including the female reproductive tract, i.e. in the uterus and ovary during the estrous cycle and pregnancy (Okuda et al. 2002, Arosh et al. 2004a, 2004b, Weems et al. 2006). Uterine and ovarian PGs are considered important factors for the regulation of reproductive events such as ovulation, luteolysis, embryo implantation, and maintenance of pregnancy (Weems et al. 2006). Generally, $\mathrm{PGE}_{2}$ exerts luteotrophic and luteoprotective actions to lengthen the lifespan of $\mathrm{CL}$ and sustain progesterone $\left(\mathrm{P}_{4}\right)$ production (Weems et al. 1997, Kotwica et al. 2003). $\mathrm{PGF}_{2 \alpha}$ is the main luteolytic agent in ruminants (McCracken et al. 1999, Skarzynski et al. 2008).

The relative proportion of both $\mathrm{PGE}_{2}$ and $\mathrm{PGF}_{2 \alpha}$ seems to be more important than their absolute values for establishment and maintenance of pregnancy (Weems et al. 1997, Arosh et al. 2004a, 2004b). Several immunological factors, including cytokines such as tumor necrosis factor- $\alpha$ (TNF), are thought to participate in luteolysis and to stimulate luteolytic $\mathrm{PGF}_{2 \alpha}$ production and output from the bovine uterus and $\mathrm{CL}$ (Miyamoto et al. 2000, Skarzynski et al. 2000, 2007, Pate \& Keyes 2001, Korzekwa et al. 2008). In ruminants, another cytokine, interferon- $\tau$ (IFNT), is considered to be responsible for the blockade of the luteolytic signal and maintenance of $\mathrm{CL}$ function in early pregnancy (Thatcher et al. 1986, Spencer et al. 2007a, 2007 b). IFNT modulates PG secretion by inhibiting the expression of oxytocin (OXT) receptor. IFNT also increases the expression of $\mathrm{PGH}$ synthase-2 (PTGS2; COX2), which leads to a shift in the PG production profile from $\mathrm{PGF}_{2 \alpha}$ toward $\mathrm{PGE}_{2}$ (Spencer et al. 1996, Bazer et al. 1997). Cytokines including TNF and interleukin (IL) have been proposed to act as mediators/modulators of IFNT actions during maternal recognition of pregnancy (Leung et al. 2000, Parent et al. 2002, 2003, Okuda et al. 2004, Lea \& Sandra 2007).

IL1A belongs to the IL1 superfamily and is known as a pro-inflammatory factor that is synthesized mainly by immune cells such as macrophages, monocytes, and dendritic cells. This pleiotropic cytokine regulates the inflammatory process, immune response, and hematopoiesis, and also regulates PG production in several 
organs and tissues (Takes et al. 1998). Besides acting as an immune factor, IL1A is one of the main cytokines that participates in the local regulation of many reproductive events. IL1A also has a role in regulating ovulation (Rae et al. 2004). The mRNAs for IL1A and IL1B (IL1 $\beta$ ) and receptor IL1R are present in the bovine $C L$ and endometrium throughout the estrous cycle (Nishimura et al. 2004, Tanikawa et al. 2005) and during early pregnancy (Leung et al. 2000). In vitro studies suggest that ILs act as local modulators of both luteolytic $\mathrm{PGF}_{2 \alpha}$ and luteotrophic $\mathrm{PGE}_{2}$ production in the bovine $\mathrm{CL}$ and endometrium (Betts \& Hansen 1992, Leung et al. 2001, Nishimura et al. 2004, Tanikawa et al. 2005).

A number of in vitro studies have also shown that IL1 ( $\alpha$ and $\beta$ ) as well as other cytokines can regulate endometrial PG secretion in a cell type-restricted manner (Betts \& Hansen 1992, Davidson et al. 1995, Tanikawa et al. 2005, 2008). Previous results suggest that stromal cells are the target of IL1A and IL1B for stimulating the production of both PGs (Tanikawa et al. 2008). The action of IL1 and IL2 on both OXT receptor (OXTR) mRNA expression and endometrial PG production may alter luteolysis (Leung et al. 2001). Recent in vitro studies from our laboratory suggest that IL1A plays some role in regulating the $\mathrm{PGF}_{2 \alpha}$ to $\mathrm{PGE}_{2}$ ratio during the estrous cycle, and that this effect is mediated via regulation of PGE synthase (Tanikawa et al. 2005, 2008). However, based on in vitro studies, there is no consensus whether IL1A has luteotrophic or luteolytic properties (Betts \& Hansen 1992, Leung et al. 2001, Tanikawa et al. 2005). Therefore, to determine the physiological role of IL1A during the estrous cycle and early pregnancy in cows, we examined the influence of IL1A on PG secretion by cultured bovine endometrial tissues obtained from cyclic or early pregnant cows (days 16-17). We also examined whether IL1A modulates the effects of IFNT on the bovine endometrium in vitro, and whether it affects $\mathrm{PG}$ and $\mathrm{P}_{4}$ secretions and the lifespan of the $\mathrm{CL}$ in vivo.

\section{Results}

\section{Experiment 1: effect of IL1A on basic and IFNT-regulated PG secretion by the bovine endometrium: in vitro}

In the present study, TNF, used as a positive control, increased in vitro secretion of both $\mathrm{PGE}_{2}$ and $\mathrm{PGF}_{2 \alpha}$ by bovine endometrium at the luteal phase $(P<0.01$; Figs $1 \mathrm{~A}$ and $2 \mathrm{~A}$ ), indicating that the tissues were reactive in the present experimental condition. Nevertheless, this cytokine did not affect any PG secretions on days 16-17 of the pregnancy $(P>0.05$; Figs $1 \mathrm{~B}$ and $2 \mathrm{~B})$.

On days $16-17$ of the estrous cycle, IL1A increased $\mathrm{PGE}_{2}$ secretion by bovine endometrium (Fig. 1A, $P<0.05)$. Nevertheless, IFNT at a dose of $30 \mathrm{ng} / \mathrm{ml}$ did not influence basal $\mathrm{PGE}_{2}$ secretion by cow endometrium

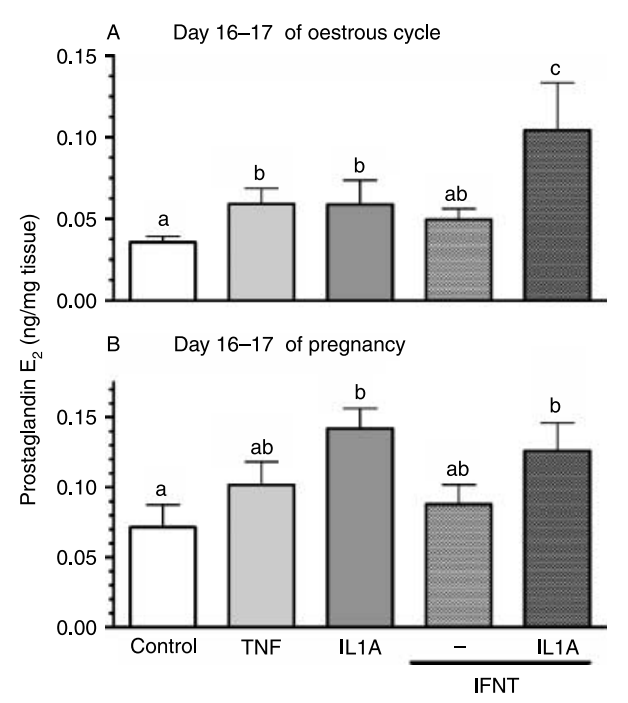

Figure $1 \mathrm{PGE}_{2}$ production by bovine endometrial tissue from cows on days 16-17 of estrous cycle (A) and pregnancy (B) in response to TNF $(0.6 \mathrm{nM})$, IL1A $(10 \mathrm{ng} / \mathrm{ml})$, IFNT $(30 \mathrm{ng} / \mathrm{ml})$, and both IL1A and IFNT. Superscript letters: $a, b$, and $c$ indicate statistical differences between control and treated groups $(P<0.05)$, as determined by one-way ANOVA, followed by the Newman-Keuls test.

collected on the same days $(P>0.05)$. However, this cytokine significantly augmented IL1A-stimulated $\mathrm{PGE}_{2}$ production on days $16-17$ of the estrous cycle $(P>0.05)$.

On days 16-17 of pregnancy, IL1A strongly increased $\mathrm{PGE}_{2}$ secretion by the bovine endometrium (Fig. 1B, $P<0.05)$. IFNT that was administered alone did not influence $\mathrm{PGE}_{2}$ secretion and did not modulate IL1A influence on $\mathrm{PGE}_{2}$ secretion on days 16-17 of pregnancy $(P>0.05)$.

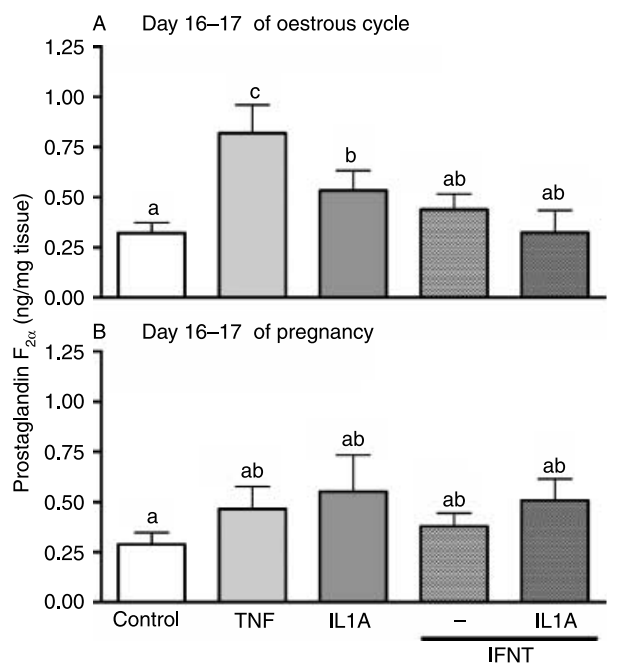

Figure $2 \mathrm{PGF}_{2 \alpha}$ production by bovine endometrial tissue from cows on days 16-17 of estrous cycle $(A)$ and pregnancy $(B)$ in response to TNF $(0.6 \mathrm{nM})$, IL1A $(10 \mathrm{ng} / \mathrm{ml})$, IFNT $(30 \mathrm{ng} / \mathrm{ml})$, and both IL1A and IFNT. Superscript letters: $a, b$, and $c$ indicate statistical differences between control and treated groups $(P<0.05)$, as determined by one-way ANOVA, followed by the Newman-Keuls test. 
IL1A increased $\mathrm{PGF}_{2 \alpha}$ production by the bovine endometrium on days $16-17$ of the estrous cycle (Fig. 2A, $P<0.05$ ). IFNT did not influence the stimulatory effect of IL1A on $\mathrm{PGF}_{2 \alpha}$ concentration on days 16-17 of the estrous cycle (Fig. 2A, $P<0.05$ ).

On days 16-17 of pregnancy, IL1A and IFNT did not influence $\mathrm{PGF}_{2 \alpha}$ production $(P>0.05$; Fig. 2B). Also, IFNT did not modulate IL1A influence on $\mathrm{PGF}_{2 \alpha}$ secretion on days $16-17$ of pregnancy $(P>0.05)$.

\section{Experiment 2: effects of IL1A on PGs, $P_{4}$ output, and the $C L$ lifespan: in vivo}

IL1A at doses of 0.1 and $1 \mu \mathrm{g}$ stimulated $\mathrm{P}_{4}$ output in peripheral blood during $24 \mathrm{~h}$ in comparison to the control cows $(P<0.01)$. Moreover, IL1A at doses of 0.1 and $1 \mu$ g elevated the total amount of secreted $\mathrm{P}_{4}$ in the blood plasma in comparison to the control cows (Table $1 ; P<0.01$ ). Administration of other selected doses of IL1A did not influence $\mathrm{P}_{4}$ concentration and total amount of secreted $\mathrm{P}_{4}$ in the blood plasma in comparison to the control cows (Fig. 3A, Table 1; $P>0.05$ ). Figure $3 \mathrm{~A}$ shows $\mathrm{P}_{4}$ concentrations in the blood plasma of control and experimental cows.

IL1A at doses of 0.1 and $1 \mu \mathrm{g}$ stimulated $\mathrm{PGE}_{2}$ output in peripheral blood during $24 \mathrm{~h}$ in comparison to the control cows $(P<0.01)$. Moreover, IL1A at doses of 0.1 and $1 \mu \mathrm{g}$ elevated the total amount of secreted $\mathrm{PGE}_{2}$ in the blood plasma in comparison to the control cows (Table $1 ; P<0.01$ ). Administration of other selected doses of IL1A did not influence $\mathrm{PGE}_{2}$ concentration and total amount of secreted $\mathrm{PGE}_{2}$ in the blood plasma in comparison to the control cows (Fig. 3B, Table 1; $P>0.05$ ). Figure $3 \mathrm{~B}$ shows $\mathrm{PGE}_{2}$ concentrations in the blood plasma of control and experimental cows.

IL1A at a dose of $10 \mu \mathrm{g}$ stimulated PGFM $(13,14-$ dihydro, 15-keto-prostaglandin $\mathrm{F}_{2 \alpha}$ ) output in peripheral blood during $12 \mathrm{~h}$ after application in comparison to the control cows $(P<0.01)$. Moreover, IL1A at doses of

Table 1 Effects of different doses of interleukin-1 $\alpha$ (IL1A) administered into the uterus on the total amounts of released progesterone $\left(\mathrm{P}_{4}\right)$, prostaglandin $\mathrm{E}_{2}\left(\mathrm{PGE}_{2}\right)$ and PGFM in cows on days 16-17 of the estrous cycle. Values indicate the area under the curve (relative units, means \pm S.E.M).

\begin{tabular}{lccc}
\hline Treatment & $\mathbf{P}_{\mathbf{4}}$ & PGE $_{\mathbf{2}}$ & PGFM \\
\hline Saline (control) & $12.50 \pm 0.94^{\mathrm{a}}$ & $8.29 \pm 1.21^{\mathrm{a}}$ & $525 \pm 198^{\mathrm{a}}$ \\
IL1A 0.001 $(\mu \mathrm{g})$ & $9.61 \pm 0.82^{\mathrm{a}}$ & $14.60 \pm 2.69^{\mathrm{a}}$ & $1494 \pm 297^{\mathrm{b}}$ \\
IL1A 0.01 $(\mu \mathrm{g})$ & $34.70 \pm 4.77^{\mathrm{a}}$ & $8.45 \pm 3.18^{\mathrm{a}}$ & $1393 \pm 404^{\mathrm{a}, \mathrm{b}}$ \\
IL1A 0.1 $(\mu \mathrm{g})$ & $57.37 \pm 18.12^{\mathrm{b}}$ & $42.24 \pm 27.16^{\mathrm{b}}$ & $1053 \pm 437^{\mathrm{a}}$ \\
IL1A 1 $(\mu \mathrm{g})$ & $75.42 \pm 26.52^{\mathrm{b}}$ & $41.05 \pm 7.73^{\mathrm{b}}$ & $630 \pm 147^{\mathrm{a}, \mathrm{b}}$ \\
IL1A 10 $(\mu \mathrm{g})$ & $51.31 \pm 15.54^{\mathrm{a}}$ & $7.65 \pm 0.48^{\mathrm{a}}$ & $941 \pm 277^{\mathrm{b}}$
\end{tabular}

The baseline was determined by means of hormone concentrations in blood collected $2 \mathrm{~h}$ before IL1A administration. Differences between hormone concentrations were analyzed using one-way ANOVA, followed by the Newman-Keuls test. ${ }^{a, b}$ Different subscript letters within a column indicate significant differences $(P<0.05)$ between treated groups.
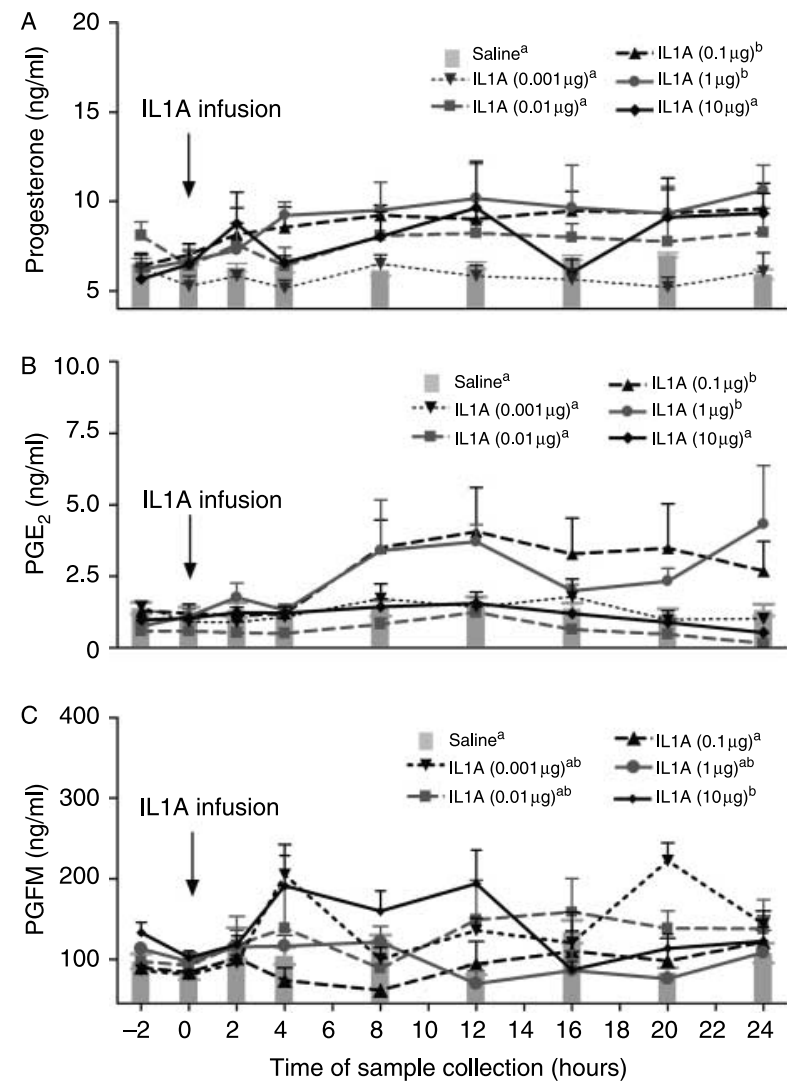

Figure 3 Concentrations of progesterone (A), $\mathrm{PGE}_{2}(\mathrm{~B})$, and PGFM (C) in peripheral blood plasma of cows infused with saline (gray bars) and various doses of IL1A (lines). All reagents were infused into the uterus. Different subscript letters indicate significant differences $(P<0.05)$ between treated groups, as assessed by repeated measures ANOVA test followed by Newman-Keuls test.

0.001 and $10 \mu$ g elevated the total amount of secreted PGFM in the blood plasma in comparison to the control cows (Table $1 ; P<0.01$ ). Administration of other doses of IL1A did not influence PGFM concentration and total amount of secreted PGFM in the blood plasma in comparison to the control cows (Fig. 3C, Table 1; $P>0.05)$. Figure $3 \mathrm{C}$ shows PGFM concentrations in the blood plasma of control and experimental cows.

IL1A at doses of 0.1 and $1 \mu \mathrm{g}$ was capable of prolonging the luteal phase of the estrous cycle - the lifespan of $\mathrm{CL}$ (Fig. 4, $P<0.05$ ). The length of the estrous cycle was prolonged to more than 30 days by infusion of IL1A at a dose of 0.1 and $1 \mu \mathrm{g}$ as compared to that in control heifers $(22.1 \pm 0.5$ days; $P<0.05)$.

\section{Discussion}

Both $\mathrm{PGE}_{2}$ and $\mathrm{PGF}_{2 \alpha}$ are secreted by the bovine endometrium throughout the estrous cycle (Miyamoto et al. 2000, Skarzynski et al. 2003) and may play opposite roles, i.e. $\mathrm{PGE}_{2}$ is luteotrophic and luteoprotective (Pratt et al. 1977, Magness et al. 1981, Kotwica et al. 2003, 


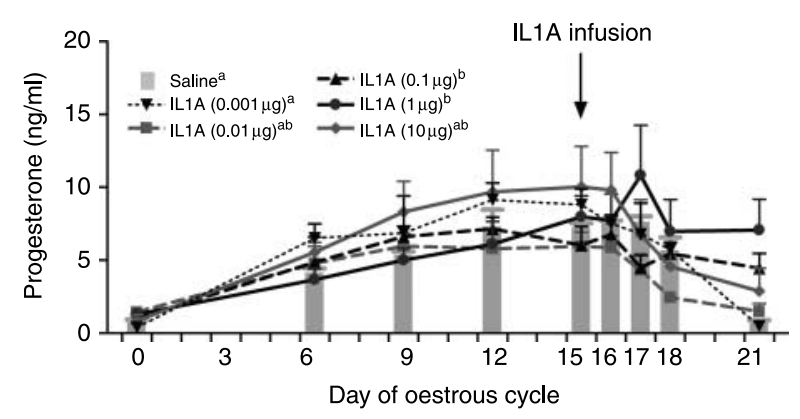

Figure 4 Concentrations of progesterone in peripheral blood plasma of cows infused with saline (gray bars) and various doses of IL1A (lines). All reagents were infused into the uterus. Different subscript letters indicate significant differences $(P<0.05)$ between treated groups, as assessed by repeated measures ANOVA test followed by Newman-Keuls test.

Weems et al. 2006), whereas $\mathrm{PGF}_{2 \alpha}$ is luteolytic (McCracken et al. 1999, Weems et al. 2006). Moreover, it has been shown that the relative proportion of $\mathrm{PGE}_{2}$ and $\mathrm{PGF}_{2 \alpha}$ secretion is thought to be more important than the absolute amounts of each PG to exert physiological effects on female reproductive functions (Murakami et al. 2001, Weems et al. 2006). One of the goals of our study was to examine whether IL1A has an effect on the secretion of PGs in the bovine endometrium during the estrous cycle and early pregnancy.

In the in vitro experiment, as expected, IL1A stimulated both luteolytic $\mathrm{PGF}_{2 \alpha}$ and luteotrophic $\mathrm{PGE}_{2}$, by the bovine endometrium during the late luteal phase of the estrous cycle. Another in vitro study has suggested that IL1A is produced in the bovine endometrium during the estrous cycle, and that it plays crucial roles in reproductive functions by regulating local $\mathrm{PGE}_{2}$ and $\mathrm{PGF}_{2 \alpha}$ production in the bovine endometrium (Tanikawa et al. 2005). This cytokine, together with IL1B, also affects bovine $\mathrm{CL}$ in vitro by modulating the secretions of both $\mathrm{PGE}_{2}$ and $\mathrm{PGF}_{2 \alpha}$, depending on the stage of the estrous cycle (Davidson et al. 1995, Nishimura et al. 2004). However, IL1A is thought to stimulate $\mathrm{PGE}_{2}$ production more strongly than IL1B in stromal cells of the bovine endometrium (Tanikawa et al. 2008). In bovine stromal cells, IL1A induced $\mathrm{PGE}_{2}$ production by increasing the expressions of PTGS2 and $\mathrm{PGE}_{2}$ synthase type $1 \mathrm{mRNA}$ and their proteins without any effects on $P G F_{2 \alpha}$ synthase (PGFS) expression (Tanikawa et al. 2008).

In the present study, IL1A increased both $\mathrm{PGE}_{2}$ and $\mathrm{PGF}_{2 \alpha}$ secretion in tissue explants from cows in the luteal phase of the estrous cycle. However, during early pregnancy, IL1A only stimulated the secretion of luteotrophic $\mathrm{PGE}_{2}$ without having any influence on the luteolytic $\mathrm{PGF}_{2 \alpha}$ secretion. Furthermore, IL1A administered into the uteri of cows in the luteal phase at doses of 0.1 and $1 \mu$ s significantly stimulated $\mathrm{PGE}_{2}$ and $\mathrm{P}_{4}$ output. Only at a dose of $10 \mu \mathrm{g}$ did IL1A increase temporally PGFM plasma concentration without effecting $\mathrm{P}_{4}$ secretion and $\mathrm{CL}$ lifespan. These findings agree with data of Leung et al. (2001) showing that proinflammatory ILs suppress OXTR expression in the late luteal phase. The cytokines IL1 and IL2 are therefore unlikely to initiate/modulate luteolysis. However, ILs can cause increased production of $\mathrm{PGF}_{2 \alpha}$ during uterine infection (Leung et al. 2001). Therefore, we suggest that during the luteal phase and early pregnancy, IL1A action is directed toward stimulating $\mathrm{PGE}_{2}$ synthesis only and increasing the $\mathrm{PGE}_{2}: \mathrm{PGF}_{2 \alpha}$ ratio. However, at the time of luteolysis and during inflammatory processes, this cytokine may stimulate $\mathrm{PGF}_{2 \alpha}$ production/output as a supporting/modulating factor rather than as a mandatory factor (Leung et al. 2001, Tanikawa et al. 2005, 2008).

Based on in vitro data (Leung et al. 2001, Tanikawa et al. 2005, 2008), it appears that some local modulators may exist during early pregnancy that switch IL $1 \mathrm{~A}$ action from stimulation of luteolytic $\mathrm{PGF}_{2 \alpha}$ to the stimulation of luteotrophic $\mathrm{PGE}_{2}$ production. One of the candidate factors is IFNT. In our study, IFNT had no significant effect on IL1A-stimulated $\mathrm{PGE}_{2}$ secretion in tissues from the pregnant endometrium, but augmented IL1A-stimulated $\mathrm{PGE}_{2}$ secretion. Moreover, in early pregnancy, IL1A strongly stimulated $\mathrm{PGE}_{2}$ production by the endometrium without having any effect on luteolytic $\mathrm{PGF}_{2 \alpha}$ output. These results suggest that during early pregnancy, IFNT modulates IL1A action and changes it toward the stimulation of luteotrophic $\mathrm{PGE}_{2}$ synthesis. In ruminants, IFNT produced by the trophoblast tissue at the time of recognition of pregnancy acts on maintaining the $\mathrm{CL}$ function (Helmer et al. 1989, Bazer et al. 1997). Data from in vivo experiments showed that IFNT inhibits $\mathrm{PGF}_{2 \alpha}$ secretion and promotes the maintenance of $\mathrm{CL}$ (Meyer et al. 1995, Spencer \& Bazer 2004). IFNT inhibits $\mathrm{PGF}_{2 \alpha}$ secretion also in vitro (Meyer et al. 1996, Spencer et al. 2007a, 2007 b). The effect of IFNT on the decrease of $\mathrm{PGF}_{2 \alpha}$ secretion in bovine endometrial cells may be due to its inhibitory actions on PGFS in the endometrium and myometrium (Arosh et al. 2004a, 2004b). Depending upon the dose and biological activity, IFNT may increase $\mathrm{PGE}_{2}$ production and stimulate PTGS2, the inducible form of cyclooxygenase in bovine endometrial cell cultures (Asselin et al. 1997, Spencer et al. 2007a, $2007 b$ ). However, there are some conflicting reports in literature about the ability of IFNT to stimulate or inhibit PG production (Xiao et al. 1999, Arosh et al. 2004a, 2004b, Okuda et al. 2004, Spencer \& Bazer 2004).

IFNT in the present study had no significant influence on the basal PG secretion from endometrial tissue explants on days $16-17$ of the estrous cycle and pregnancy. The purpose of the present work was not to determine whether IFNT regulates basal PG production but only to use the lowest effective IFNT dose that can modulate IL1A-stimulated PG production exclusively. Therefore, according to Takahashi et al. (2003) and Okuda et al. (2004), we used IFNT at a relatively small dose of $30 \mathrm{ng} / \mathrm{ml}$ that shows bioactivity and was able to 
influence TNF-regulated $\mathrm{PGF}_{2 \alpha}$ production. Moreover, some differences in IFNT action on basal PG production depend on the type and biological activity of IFNT used in the studies as well as on diverse doses (Asselin et al. 1997, Parent et al. 2002, Takahashi et al. 2003, Spencer et al. 2007a, 2007b).

The results of the in vitro experiment were supported by the in vivo experiment, which showed that an infusion of IL1A at doses of 0.1 and $1 \mu \mathrm{g}$ increased plasma concentrations of $\mathrm{P}_{4}$ and $\mathrm{PGE}_{2}$. Besides, we found that infusion of IL1A at a dose of $10 \mu \mathrm{g}$ increased PGFM plasma concentration that may reflect the stimulation of luteolytic $\mathrm{PGF}_{2 \alpha}$ secretion by the uterus. Thus, IL1A as well other cytokines (e.g. IFNs, TNF) has a diverse spectrum of biological activities, including stimulation of different metabolites of arachidonic acid (luteotrophic versus luteolytic), cell proliferation and differentiation, and induction of apoptosis (Beutler \& Huffel 1994, Dinarello 1994, 1996, Skarzynski et al. 2003, 2007, Korzekwa et al. 2008). The ability of cytokines to exert a wide variety of effects is likely due to actions exerted via multiple signaling pathways involving two or more distinct receptors and numerous intracellular mediators/ pathways (Arend 1991, Beutler \& Van Huffel 1994, Colotta et al. 1994, Dinarello 1994, Tartaglia \& Goeddel 1994, Korzekwa et al. 2008). The highest dose of IL1A may act not only locally on the endometrial cells, but also remotely on other structures of the reproductive tract (i.e. on epithelium of blood vessels, immune cells, myometrium, etc.), inducing uterine $\mathrm{PGF}_{2 \alpha}$ production. In our study, $10 \mu \mathrm{g}$ of IL1A induced temporal rise in $\mathrm{PGF}_{2 \alpha}$ secretion, but didn't have any effect on $\mathrm{P}_{4}$ production or the CL lifespan. Thus, for such luteolytic action of IL1A, both sites of action are needed (uterus and CL), and direct amplification of luteolytic signals in the $\mathrm{CL}$ is mandatory (Nishimura et al. 2004, Skarzynski et al. 2008). It is controversial to suppose that IL1A can participate in luteolysis as one of mandatory auto-paracrine factors inducing $\mathrm{PGF}_{2 \alpha}$ production and output in the endometrium (Tanikawa et al. 2005). Our in vivo experiment showed that IL1A administered directly into the uterus at the late luteal stage of the estrous cycle significantly stimulated $\mathrm{P}_{4}$ and $\mathrm{PGE}_{2}$ concentrations and prolonged $\mathrm{CL}$ lifespan. These findings suggest that in vivo, IL1A plays mainly luteoprotective roles. The present results show that IL1A possibly has a direct positive influence on the $C L$ function via the stimulation of $\mathrm{P}_{4}$ secretion. However, the IL1A indirect role seems also probable because of its influence on $\mathrm{PGE}_{2}$ secretion. It should also be noted that the relatively small effect of IL1A treatments on PG levels was shown in in vitro experiments comparing with in vivo effects. The endometrium is composed of epithelial and stromal cells and also blood vessels and leukocytes. This mixture of cell types is the evident source of the basal levels of PGs as well as the source of PGs that were secreted after stimulation during the in vitro experiments. However, in in vivo procedures, many other tissues including the main bloodstream can respond to IL1A. In response to IL1A, these tissues may release some PGs, the amounts of which can be estimated by jugular vein sampling.

In summary, IL1A may play some autocrine or paracrine roles in regulating PG production in the endometrium during the estrous cycle and early pregnancy in cattle. Although IL1A may stimulate in vitro luteolytic $\mathrm{PGF}_{2 \alpha}$ secretion during the estrous cycle, in vivo it acts only as a luteotrophic factor. IL1A increased luteotrophic $\mathrm{PGE}_{2}$ and $\mathrm{P}_{4}$ output, inhibiting spontaneous luteolysis and prolonging the lifespan of the bovine CL. These luteotrophic effects may result in appropriate development and function of the bovine $\mathrm{CL}$ during the estrous cycle and early pregnancy. Moreover, IFNT produced during the early pregnancy can modulate IL1A action and change it toward the stimulation of luteotrophic $\mathrm{PGE}_{2}$ synthesis. These luteotrophic effects of IL1A during early pregnancy may support early embryo development and implantation, and may play an additional role in the maternal recognition of pregnancy in cattle.

\section{Materials and Methods}

\section{Animals}

All procedures were approved by the Local Animal Care and Use Committee in Olsztyn, Poland (agreements no. 73/2002/N and $06 / 2007 / \mathrm{N}$ ).

For all experiments, normally cycling Holstein/Polish Black and White ( $75 / 25 \%$; respectively) cows (4-6 lactations; $n=39$ ) were chosen. The animals were culled by the owner from two dairy cow herds (years 2005-2008) because of their low milk production. In order to carry out these experiments, estrus of the cows was synchronized using two analogs of $\mathrm{PGF}_{2 \alpha}$ (dinoprost, Dinolytic; Upjohn - Pharmacia N.V.S.A.) injections with an 11-14-day interval, as recommended and described recently (Skarzynski et al. 2009). The onset of estrus was determined by observing its signs (i.e. vaginal mucus, standing behavior) and was confirmed by a veterinarian by transrectal internal geniatalia ultrasonography (USG) examination using Draminski Animal profi Scanner (Draminski Electronics in Agriculture, Olsztyn, Poland). Only the cows with behavioral signs of estrus and USG confirmation were chosen for the study. Estrus was considered as day 0 of the estrous cycle.

\section{Experimental procedure}

Experiment 1: the effect of IL 1A on basal and IFNT-regulated PG secretion by the bovine endometrium: in vitro

Bovine uteri were obtained at a local slaughterhouse (Zaklady Miesne 'Warmia' in Biskupiec) within 20 min of exsanguination and were transported on ice to the laboratory within $40 \mathrm{~min}$. Before slaughter, the cows were assigned into two groups, i.e. pregnant and cyclic animals. The animals were randomly chosen for the pregnant group and underwent 
artificial insemination with semen from the same bull. Pregnancy was confirmed by flushing the uterus for the collection of the viable embryo as described recently (Woclawek-Potocka et al. 2009). Endometria were obtained from cows on days 16-17 of the cycle $(n=7)$ and on days 16-17 of pregnancy $(n=6)$. Moreover, the flushed uterine fluid was collected and the antiviral activity of IFNT was measured, as described recently (Gierek et al. 2006). In addition, the sensitivity of cultured endometrial tissue (days 16-17) to OXT treatment was tested. Only nonpregnant bovine endometrium, in the late luteal and follicular phases of the cycle, is sensitive to OXT treatment and $\mathrm{PGF}_{2 \alpha}$ release (Miyamoto et al. 2000). Therefore, only the uteri which responded properly to those tests were chosen for the respective pregnancy groups as described previously (Woclawek-Potocka et al. 2009).

The endometrial tissues were incubated in a shaking water bath at $37^{\circ} \mathrm{C}$ as described previously (Miyamoto et al. 2000, Tanikawa et al. 2005). Shortly, endometrial strips were washed thrice in sterile saline containing $100 \mathrm{IU} / \mathrm{ml}$ penicillin and $100 \mu \mathrm{g} / \mathrm{ml}$ streptomycin. The tissues were then cut into small pieces $(\sim 20-30 \mathrm{mg})$. The individual pieces of endometrial tissues were placed in culture glass tubes $(12 \times 75 \mathrm{~mm})$ containing $2 \mathrm{ml}$ culture medium (DMEM and Hams F-12 medium 1:1(v/v); Sigma Chemical Co. \#8900) supplemented with $0.1 \%$ BSA (Sigma, \#A9056), $5 \mathrm{ng} / \mathrm{ml}$ sodium selenite (Sigma, \#S1382), $0.5 \mathrm{mM}$ ascorbic acid (Sigma, \#A1417), and $20 \mu \mathrm{g}$ gentamycin (Sigma, \#G1397). Media were continuously gassed with $5 \% \quad \mathrm{CO}_{2}$ during incubation.

After 1-h preincubation, endometrial slices were exposed to IL1A (10 ng/ml), IFNT (30 ng/ml), both IL1A and IFNT, or TNF $(0.6 \mathrm{nM})$ as a positive control. IL1A (HL-18) was obtained from Dainippon Pharmaceutical Co., Osaka, Japan. Recombinant bovine IFNT, classified into the rb-1a group, was produced by an Autographa californica nuclear polyhedrosis virus expression system, and was a gift from Dr Hitomi Takahashi (National Institute of Livestock and Grassland Science, Tsukuba, Japan). Doses of IL1A, TNF, and IFNT were chosen based on our previous studies (Miyamoto et al. 2000, Takahashi et al. 2003, Okuda et al. 2004, Tanikawa et al. 2005).

After $18 \mathrm{~h}$ of stimulation, the conditioned media were collected in tubes with $10 \mu \mathrm{l}$ EDTA, 1\% aspirin (Sigma, \#A1093), solution ( $\mathrm{pH} 7.3)$, and frozen at $-20{ }^{\circ} \mathrm{C}$ until $\mathrm{PGF}_{2 \alpha}$ and $\mathrm{PGE}_{2}$ measurements. The tissues were blotted with filter paper and weighed to obtain the concentration per gram of tissue.

Experiment 2: effects of IL1A on PGs, $P_{4}$ output, and the $C L$ lifespan: in vivo studies

On day 16 of the cycle, a polyvinyl catheter was inserted into the jugular vein for frequent collection of blood samples (Skarzynski et al. 2003). To test the hypothesis that IL1A acts locally on the bovine uterus to regulate PG secretion and the lifespan of the bovine $\mathrm{CL}$, we administered saline ( $5 \mathrm{ml} ; n=5)$ or $0.001(n=3), 0.01(n=5), 0.1(n=5), 1(n=5)$, and $10 \mu \mathrm{g}$ of IL1A (dissolved in $5 \mathrm{ml}$ of saline) directly into the uterine lumen as a single intrauterine infusion described previously (Skarzynski et al. 2007). Blood was collected $2 \mathrm{~h}$ before and every $2-4 \mathrm{~h}$ after IL1A administration during $24 \mathrm{~h}$, via cannula placed in the jugular vein. Furthermore, blood was collected every 1,3 , or 6 days during the estrous cycle. Plasma was obtained by centrifugation $\left(3000 \mathrm{~g}, 10 \mathrm{~min}, 4{ }^{\circ} \mathrm{C}\right)$ and stored at $-20^{\circ} \mathrm{C}$ until $\mathrm{PGE}_{2}, \mathrm{PGFM}$, and $\mathrm{P}_{4}$ assessment.

\section{Determination of hormone concentrations}

The concentrations of $\mathrm{PGE}_{2}$ in plasma samples and culture medium were determined with the direct enzyme immunoassay (EIA) test, as described previously (Skarzynski et al. 2000, 2003). The $\mathrm{PGE}_{2}$ standard curve ranged from 0.07 to $20 \mathrm{ng} / \mathrm{ml}$. The intra- and interassay coefficients of variation (CV) were on average 6.9 and $9.7 \%$ respectively.

$\mathrm{PGF}_{2 \alpha}$ concentration in the culture medium was assayed using direct EIA as described previously (Skarzynski et al. 2000). The $\mathrm{PGF}_{2 \alpha}$ standard curve was produced for $\mathrm{PGF}_{2 \alpha}$ concentrations ranging from 15.6 to $4000 \mathrm{pg} / \mathrm{ml}$. The intra- and interassay CV were on average 7.9 and $10.4 \%$ respectively.

The concentration of PGFM in the culture medium was determined with the direct EIA test, as described previously (Skarzynski et al. 2003). The anti-PGFM serum (WS4468-5) was donated by Dr W J Silvia, University of Kentucky, Lexington, KY, USA. The PGFM standard curve ranged from 15.6 to $4000 \mathrm{pg} / \mathrm{ml}$. The intra- and interassay CV were on average 6.1 and $8.7 \%$ respectively.

$\mathrm{P}_{4}$ concentrations in plasma were assayed using direct EIA as described previously (Skarzynski et al. 2003). The $P_{4}$ standard curve ranged from 0.07 to $20 \mathrm{ng} / \mathrm{ml}$. The intra- and interassay CV were on average 6.9 and $9.7 \%$ respectively.

\section{Statistical analysis}

Least-squares means and S.E.M. were determined. Differences in the length of the estrous cycle and in vitro PG production were analyzed using one-way ANOVA followed by Newman-Keuls multiple comparison test (ANOVA; GraphPAD PRISM Version 4.00, San Diego, CA, USA). Moreover, the differences in in vitro PG production between control and experimental groups were analyzed using paired Student's $t$-test (GraphPAD PRISM) $\mathrm{P}_{4}$ and arachidonic acid metabolites ( $\mathrm{PGE}_{2}, \mathrm{PGFM}$ ) in the jugular plasma samples were analyzed using a repeated measure design approach (Skarzynski et al. 2003, 2007). All analyses were performed using repeated measures ANOVA tests followed by Newman-Keuls multiple comparison test (GraphPAD PRISM; $P<0.05$ was considered significant). Moreover, in the in vivo study, the total amounts of released $\mathrm{P}_{4}, \mathrm{PGE}_{2}$, and PGFM were shown by the areas under the curve (relative units; Table 1) and analyzed using one-way ANOVA followed by Newman-Keuls multiple comparison test (ANOVA; GraphPAD PRISM).

\section{Declaration of interest}

The authors declare that there is no conflict of interest that could be perceived as prejudicing the impartiality of the research reported. 


\section{Funding}

The research was supported by the Grants-in-Aid for Scientific Research of the Polish Ministry of Sciences and Higher Education (2P06K 02529 and N 30832 79 33), the Japanese-Polish Joint Research Project under an agreement between the Japanese Society of Promotion of Sciences and Polish Academy of Sciences, and in part by the Research Fund from the Livestock Technology Association (LTA), Japan.

\section{Acknowledgements}

We thank Dr W J Silvia, University of Kentucky, Lexington, USA for PGFM antisera; Dr S Okrasa of University of Warmia and Mazury for progesterone antisera; and Dainippon Pharmaceutical Co., Ltd, Osaka, Japan for IL1A and TNF; Dr H Takahashi for IFNT. The authors thank Henryk Jablonski of the experimental farm of Polish Academy of Sciences in Baranowo, Krystyna and Zenon Kasinski of the animal farm in Watkowice, and Maciej Baurycza of the animal farm in Cieszymowo, Poland for their excellent cooperation and permission to use the animals for the experiments and tissue collection. The authors are grateful to Draminski Electronics in Agriculture, Poland for their cooperation and possibility to use the USG scanner. We are also grateful to Marek Domin, the owner of the slaughterhouse (Zaklady Miesne 'Warmia' in Biskupiec), for the permission to collect material.

\section{References}

Arend WP 1991 Interleukin 1 receptor antagonist. A new member of the interleukin 1 family. Journal of Clinical Investigation 88 1445-1451.

Arosh JA, Banu SK, Chapdelaine P, Madore E, Sirois J \& Fortier M 2004a Prostaglandin biosynthesis, transport, and signaling in corpus luteum: a basis for autoregulation of luteal function. Endocrinology 145 2551-2560.

Arosh JA, Banu SK, Kimmins S, Chapdelaine P, Maclaren LA \& Fortier MA $2004 b$ Effect of interferon- $\tau$ on prostaglandin biosynthesis, transport, and signaling at the time of maternal recognition of pregnancy in cattle: evidence of polycrine actions of prostaglandin $\mathrm{E}_{2}$. Endocrinology 145 5280-5293.

Asselin E, Lacroix D \& Fortier MA 1997 IFN- $\tau$ increases $\mathrm{PGE}_{2}$ production and COX-2 gene expression in the bovine endometrium in vitro. Molecular and Cellular Endocrinology 132 117-126.

Bazer FW, Spencer TE \& Ott TL 1997 Interferon $\tau$ : a novel pregnancy recognition signal. American Journal of Reproductive Immunology 37 412-420.

Betts JG \& Hansen PJ 1992 Regulation of prostaglandin secretion from epithelial and stromal cells of the bovine endometrium by interleukin-1 $\beta$, interleukin-2, granulocyte-macrophage colony stimulating factor and tumor necrosis factor- $\alpha$. Life Sciences 51 1171-1176.

Beutler B \& Van Huffel C 1994 Unraveling function in the TNF ligand and receptor families. Sciences 264 667-668.

Colotta F, Dower SK, Sims JE \& Mantovani A 1994 The type II 'decoy' receptor: a novel regulatory pathway for interleukin 1. Immunology Today 15 562-566.

Davidson JA, Tiemann U, Betts JG \& Hansen PJ 1995 DNA synthesis and prostaglandin secretion by bovine endometrial cells as regulated by interleukin-1. Reproduction, Fertility, and Development 7 1037-1043.

Dinarello CA 1994 The interleukin-1 family: 10 years of discovery. FASEB Journal 8 1314-1325.

Dinarello CA 1996 Biologic basis for interleukin-1 in disease. Blood 87 2095-2147.
Gierek D, Baczyńska D, Ugorski M, Bazer F, Kurpisz M, Bednarski T, Gorczykowski M \& Chełmońska-Soyta A 2006 Differential effect of IFN- $\tau$ on proliferation and distribution of lymphocyte subsets in one-way mixed lymphocyte reaction in cows and heifers. Journal of Reproductive Immunology 71 126-131.

Helmer SD, Gross TS, Newton GR, Hansen PJ \& Thatcher WW 1989 Bovine trophoblast protein-1 complex alters endometrial protein and prostaglandin secretion and induces an intracellular inhibitor of prostaglandin synthesis in vitro. Journal of Reproduction and Fertility 87 421-430.

Korzekwa A, Murakami S, Wocławek-Potocka I, Bah MM, Okuda K \& Skarzynski DJ 2008 The influence of tumor necrosis factor $\alpha$ (TNF) on the secretory function of bovine corpus luteum: TNF and its receptors expression during the estrous cycle. Reproductive Biology $\mathbf{8}$ 245-262.

Kotwica J, Skarzynski D, Mlynarczuk J \& Rekawiecki R 2003 Role of prostaglandin $\mathrm{E}_{2}$ in basal and noradrenaline-induced progesterone secretion by the bovine corpus luteum. Prostaglandins \& Other Lipid Mediators 70 351-359.

Lea RG \& Sandra O 2007 Immunoendocrine aspects of endometrial function and implantation. Reproduction 134 389-404.

Leung ST, Derecka K, Mann GE, Flint AP \& Wathes DC 2000 Uterine lymphocyte distribution and interleukin expression during early pregnancy in cows. Journal of Reproduction and Fertility 119 25-33.

Leung ST, Cheng Z, Sheldrick EL, Derecka K, Flint AP \& Wathes DC 2001 The effects of lipopolysaccharide and interleukins- $1 \alpha,-2$ and -6 on oxytocin receptor expression and prostaglandin production in bovine endometrium. Journal of Endocrinology 168 497-508.

Magness RR, Huine JM \& Hoyer GL 1981 Effect of chronic ipsilateral or collateral intrauterine infusion of prostaglandin $E_{2}\left(\mathrm{PGE}_{2}\right)$ on luteal function of unilaterally ovariectomized ewes. Prostaglandins and Medicine 6 389-401.

McCracken JA, Custer EE \& Lamsa JC 1999 Luteolysis: a neuroendocrinemediated event. Physiological Reviews 79 263-323.

Meyer MD, Hansen PJ, Thatcher WW, Drost M \& Badinga L 1995 Extension of corpus luteum life span and reduction of uterine secretion of prostaglandin $F_{2 \alpha}$ of cows in response to recombinant interferon- $\tau$. Journal of Dairy Science 78 1921-1931.

Meyer MD, Desnoyers GD, Oldick B, Thatcher WW, Drost M, Schalue TK \& Roberts RM 1996 Treatment with recombinant interferon- $\tau$ in uteroattenuates secretion of prostaglandin $\mathrm{F}$ from cultured endometrial cells. Journal of Dairy Science 79 1375-1384.

Miyamoto Y, Skarzynski DJ \& Okuda K 2000 Is tumor necrosis factor $\alpha$ a tigger for the initiation of endometrial prostaglandin $F_{2 \alpha}$ release at luteolysis in cattle? Biology of Reproduction 62 1109-1115.

Murakami S, Miyamoto Y, Skarzynski DJ \& Okuda K 2001 Effects of tumor necrosis factor-alpha on secretion of prostaglandins $E_{2}$ and $F_{2 \alpha}$ in bovine endometrium throughout the estrus cycle. Theriogenology $\mathbf{5 5}$ 1667-1678.

Nishimura R, Bowolaksono A, Acosta TJ, Murakami S, Piotrowska KK, Skarżyński DJ \& Okuda K 2004 Possible role of interleukin-1 in the regulation of bovine corpus luteum throughout the luteal phase. Biology of Reproduction 71 1688-1693.

Okuda K, Miyamoto Y \& Skarzynski DJ 2002 Regulation of endometrial prostaglandin $F_{2 \alpha}$ synthesis during luteolysis and early pregnancy in cattle. Domestic Animal Endocrinology 23 255-264.

Okuda K, Kasahara Y, Murakami S, Takahashi H, Woclawek-Potocka I \& Skarzynski DJ 2004 Interferon- $\tau$ blocks the stimulatory effect of tumor necrosis factor- $\alpha$ on prostaglandin F2alpha synthesis by bovine endometrial stromal cells. Biology of Reproduction 70 191-197.

Parent J, Chapdelaine P, Sirois J \& Fortier MA 2002 Expression of microsomal prostaglandin E synthase in bovine endometrium: coexpression with cyclooxygenase type 2 and regulation by interferon- $\tau$. Endocrinology 143 2936-2943.

Parent J, Villeneuve C, Alexenko AP, Ealy AD \& Fortier MA 2003 Influence of different isoforms of recombinant trophoblastic interferonson prostaglandin production in cultured bovine endometrial cells. Biology of Reproduction 68 1035-1043.

Pate JL \& Keyes LP 2001 Immune cells in the corpus luteum: friends or foes. Reproduction 122 665-676.

Pratt BR, Butcher RL \& Inskeep EK 1977 Antiluteolytic effect of the conceptus and of $\mathrm{PGE}_{2}$ in ewes. Journal of Animal Science 45 784-791. 
Rae MT, Niven D, Ross A, Forster T, Lathe R, Critchley HO, Ghazal P \& Hillier SG 2004 Steroid signalling in human ovarian surface epithelial cells: the response to interleukin- $1 \alpha$ determined by microarray analysis. Journal of Endocrinology 183 19-28.

Skarzynski DJ, Miyamoto Y \& Okuda K 2000 Production of prostaglandin $\mathrm{F}_{2 \alpha}$ by cultured bovine endometrial cells in response to tumor necrosis factor- $\alpha$ : cell type specificity and intracellular mechanisms. Biology of Reproduction 62 1116-1120.

Skarzynski DJ, Bah MM, Deptula KM, Woclawek-Potocka I, Korzekwa A, Shibaya M, Pilawski W \& Okuda K 2003 Roles of tumor necrosis factor $\alpha$ of the estrus cycle in cattle: an in vivo study. Biology of Reproduction 69 1907-1913.

Skarzynski DJ, Woctawek-Potocka I, Korzekwa A, Bah MM, Piotrowska KK, Barszczewska BB \& Okuda K 2007 Infusion of exogenous tumor necrosis factor dose dependently alters the length of the luteal phase in cattle: differential responses to treatment with indhomethacin and a nitric oxide synthase inhibitor (L-NAME). Biology of Reproduction 76 619-627.

Skarzynski DJ, Ferreira-Dias G \& Okuda K 2008 Regulation of luteal function and corpus luteum regression in cows: hormonal control, immune mechanisms and intercellular communication. Reproduction in Domestic Animals 43 (Supplement 2) 57-65.

Skarzynski DJ, Siemieniuch M, Pilawski W, Woclawek-Potocka I, Bah MM, Majewska M \& Jaroszewski JJ 2009 In vitro assessment of progesterone and prostaglandin $\mathrm{E}_{2}$ production by the corpus luteum in cattle following pharmacological synchronization of the estrus. Journal of Reproduction and Development 55 170-176.

Spencer TE \& Bazer FW 2004 Conceptus signals for establishment and maintenance of pregnancy. Reproductive Biology and Endocrinology 249.

Spencer TH, Ott TL \& Bazer FW $1996 \tau$-Interferon: pregnancy recognition signal in ruminants. Proceedings of the Society for Experimental Biology and Medicine 213 215-229.

Spencer TE, Johnson GA, Bazer FW \& Burghardt RC 2007 a Fetal-maternal interactions during the establishment of pregnancy in ruminants. Society of Reproduction and Fertility 64 (Supplement) 379-396.

Spencer TE, Johnson GA, Bazer FW, Burghardt RC \& Palmarini M 2007b Pregnancy recognition and conceptus implantation in domestic ruminants: roles of progesterone, interferons and endogenous retroviruses. Reproduction, Fertility, and Development 19 65-78.

Takahashi $H$, Inumaru S, Takahashi $M$, Watanabe S, Iga $K$, Yokomizo $Y$, Geshi M, Okano A \& Okuda K 2003 Biological activity of recombinant bovine interferon- $\tau$ using an Autographa californica nuclear polyhedrosis virus expression system. Journal of Reproduction and Development 49 433-440.

Takes L, Kovacs EJ, Smith MR, Young HA \& Durum SK 1998 Detection of IL- $1 \alpha$ and IL- $1 \beta$ gene expressions by in situ hybridization. Tissue localization of IL-1 mRNA in the normal C57BL/6 mouse. Journal of Immunology 141 3081-3087.

Tanikawa M, Acosta TJ, Fukui T, Murakami S, Korzekwa A, Skarzynski DJ, Piotrowska KK, Park C \& Okuda KK 2005 Regulation of prostaglandin synthesis by interleukin- $1 \alpha$ in bovine endometrium during the estrous cycle. Prostaglandins \& Other Lipid Mediators 78 279-290.

Tanikawa M, Lee HY, Majewska M, Skarzynski DJ, Lee DS, Park CK, Acosta TJ, Okuda K \& Park SB 2008 Regulation of prostaglandin biosythesis by interleukin-1 in cultured bovine endometrail cells. Journal of Endocrinology 199 425-434.

Tartaglia LA \& Goeddel DV 1994 Two TNF receptors. Immunology Today 13 151-153.

Thatcher WW, Bazer FW, Sharp DC \& Roberts RM 1986 Interrelationships between uterus and conceptus to maintain corpus luteum function in early pregnancy: sheep, cattle, pigs and horses. Journal of Animal Science 62 (Supplement 2) 25-46.

Weems YS, Bridges PJ, Tanaka Y, Sasser RG, LeaMaster BR, Vincent DL \& Weems CW $1997 \mathrm{PGE}_{1}$ or $\mathrm{PGE}_{2}$ not $\mathrm{LH}$ regulates secretion of progesterone in vitro by the 88-90 day ovine corpus luteum of pregnancy. Prostaglandins 53 337-353.

Weems CW, Weems YS \& Randel RD 2006 Prostaglandins and reproduction in female farm animals. Veterinary Journal 171 206-228.

Woclawek-Potocka I, Komiyama J, Saulnier-Blache JS, Brzezicka E, Bah MM, Okuda K \& Skarzynski DJ 2009 Lysophosphatic acid modulates prostaglandin secretion in the bovine uterus. Reproduction 137 95-105.

Xiao CW, Murphy BD, Sirois J \& Goff AK 1999 Down-regulation of oxytocin-induced cyclooxygenase-2 and prostaglandin $\mathrm{F}$ synthase expression by interferon- $\tau$ in bovine endometrial cells. Biology of Reproduction 60 656-663.

Received 2 August 2009

First decision 4 September 2009

Revised manuscript received 9 December 2009

Accepted 22 December 2009 